Article

\title{
Synthesis of Resorcinol Derivatives and their Effects on Melanin Production
}

\author{
Yoshihiro Tokudome ${ }^{1, * \mathbb{D}}$, Tsuyoshi Hoshi ${ }^{1}$, Sayaka Mori ${ }^{2}$ and Ichiro Hijikuro ${ }^{2}$ \\ 1 Laboratory of Dermatological Physiology, Faculty of Pharmacy and Pharmaceutical Sciences, \\ Josai University, 1-1 Keyakidai, Sakado, Saitama 350-0295, Japan; gkm1121@josai.ac.jp \\ 2 Farnex Incorporated, Tokyo Institute of Technology Yokohama Venture Plaza 4259-3, Nagatsuta-cho, \\ Midori-ku, Yokohama, Kanagawa 226-8510, Japan; smori@farnex.co.jp (S.M.); ihijikuro@farnex.co.jp (I.H.) \\ * Correspondence: tokudome@josai.ac.jp
}

Received: 5 June 2020; Accepted: 8 July 2020; Published: 11 July 2020

check for updates

\begin{abstract}
Several resorcinol derivatives were synthesized and their effects on the survival rate of B16 murine melanoma cells, melanin production, and tyrosinase activity were investigated with an aim to evaluate their skin whitening effect. Twelve resorcinol derivatives were synthesized by esterification with three functional groups (L-ascorb-6-yl, ethyl, and glyceryl) linked via four alkyl chains of varying lengths $(n=2-5)$ at the 4-position. The structures of the 12 resorcinol derivatives were confirmed by Nuclear Magnetic Resonance (NMR). The derivatives were added to B16 murine melanoma cells and the melanin contents in the cells and culture medium were measured. To measure the tyrosinase activity, the substrate L-DOPA was added to a mushroom-derived tyrosinase solution, and the inhibition of the tyrosinase activity was determined. At $10 \mu \mathrm{M}$, the resorcinol derivatives did not affect the survival of the B16 murine melanoma cells, but the melanin content was reduced. At $1 \mu \mathrm{M}$, the derivatives significantly inhibited the tyrosinase activity in the mushroom-derived tyrosinase solution. A plot of the inhibitory effect on melanin production against the cLogP value for each resorcinol derivative indicated that the highest inhibition occurred at a cLogP value of approximately 2. Therefore, these resorcinol derivatives are expected to serve as effective skin whitening agents.
\end{abstract}

Keywords: melanin; resorcinol derivative; skin whitening; tyrosinase

\section{Introduction}

Human skin color is affected by the quantities of three pigments: melanin, hemoglobin, and carotene. In particular, melanin plays the most important role [1-3]. Melanin is an indole substance produced by the enzymatic oxidation of tyrosine. Melanin is a key pigment that absorbs ultraviolet radiation, serving as a biological defense for the skin. Melanin is produced by melanosomes in epidermal basal cells (melanocytes) [4]. Excessive melanin deposition in the epidermal layer may cause liver spots (age spots), senile lentigines, and other pigmentation disorders. Excessive melanin production and reduced melanin excretion, associated with abnormal melanin turnover, may either cause melanin deposition in the epidermal layer or pigmentation disorders.

Tyrosinase and tyrosinase-related proteins 1 and 2 (TRP1 and TRP2) are oxidases that catalyze melanin production by hydroxylating the amino acid, tyrosine to 3,4-dihydroxy-L-phenylalanine (DOPA) and oxidizing DOPA to dopaquinone. In conjunction with these processes, melanin is produced in two ways: (1) TRP2 isomerizes the pigmented intermediate, dopachrome to 5,6-dihydroxyindole-2-carboxylic acid (DHICA) [5,6], which is oxidized by TRP1 [7] and melanin is eventually produced by polymerization; (2) TRP2 does not isomerize the pigmented intermediate, dopachrome. Instead, dopachrome is spontaneously oxidized to 5,6-dihydroxyindole (DHI), which is oxidized by tyrosinase [8,9] and melanin is eventually produced by polymerization, as in (1) [10]. There are 
various methods that can be used to prevent skin pigmentation. Commercially available skin-whitening cosmetics possess various mechanisms of action, including the inhibition of melanin production-related enzymes and signal transmitters, the enhancement of melanin excretion, and DOPA reduction. As tyrosinase plays an important role in melanin production, many skin-whitening substances with tyrosinase inhibitory effects exist. The main substances with tyrosinase inhibitory effects include arbutin [11], kojic acid [12], and 4-n-butylresorcinol [13]. Linoleic acid exhibits tyrosinase decomposition-enhancing effects [14,15] and chamomile essence inhibits endothelin, a melanin production-enhancing factor [16].

The compound 4-n-butylresorcinol is a resorcinol derivative with a butyl group. Although 4-n-butylresorcinol is unstable and possesses skin irritant and bactericidal effects, it also has tyrosinase inhibitory effects [13]. Compared with arbutin and kojic acid, 4-n-butylresorcinol shows potent tyrosinase inhibitory effects at lower doses [17]. Additionally, it exhibits TRP1 inhibitory effects, which results in the inhibition of melanin production [18]. Therefore, it potentially has skin-whitening effects.

In the present study, we aimed to develop skin-whitening agents. A number of resorcinol derivatives were synthesized, and their effects were compared with those of 4-n-butylresorcinol in B16 murine melanoma cells. Along with cytotoxicity, their effects on the amount of melanin produced and the mechanism used to reduce the amount of melanin, based on their tyrosinase activity, were investigated. Using the total amount of melanin produced as an index, the usefulness of each resorcinol derivative as a skin-whitening agent was evaluated.

\section{Materials and Methods}

\subsection{Reagents}

Dulbecco's Modified Eagle's Medium (DMEM)—dimethyl sulfoxide (DMSO), 0.4\% (w/v) trypan blue solution, melanin standard, benzylsulfonyl fluoride (BSF), 2-amino-2-methyl-1,3-propanediol (Tris), and Cell-LyEX-were purchased from Fujifilm Wako Pure Chemical Industries, Ltd. (Osaka, Japan). Fetal bovine serum (FBS) was purchased from Nichirei Corporation (Tokyo, Japan). Phosphate buffered saline (PBS) was obtained from Takara Bio Inc. (Otsu, Shiga, Japan). The 0.5\% trypsin-EDTA (ethylenediaminetetraacetic acid) was purchased from Life Technologies Japan (Tokyo, Japan). Bovine serum albumin (BSA), mushroom tyrosinase, 3,4-dihydroxy-L-phenylalanine (L-DOPA), and sodium orthovanadate $90 \%$ were purchased from Sigma-Aldrich Co. (St. Louis, MO, USA).

\subsection{Chemicals}

In this study, 4-n-butyl resorcinol was used as the positive control, as shown in Figure 1. Three different types of resorcinol derivatives, varied at the $\mathrm{R}$ position, were synthesized, as described in Section 2.3, into ethyl group derivatives E-Cn $(n=2-5)$, glyceryl group derivatives G-C $(n=2-5)$, and ascorbyl group derivatives A-Cn $(n=2-5)$ ( $n$ indicates the number of carbon atoms in the methylene chains $\left(-\left(\mathrm{CH}_{2}\right) \mathrm{n}-\right)$ between the benzene ring and the carbonyl group). cLogP values were calculated in Chem Bio Draw (Bio Byte Corp., Claremont, CA, USA). Table 1 shows sample names, molecular weights, and cLogP of resorcinol derivatives. The synthetic route of each resorcin derivative is shown in Figure 1 and the methods used to synthesize the various derivatives are presented in the supplementary materials information.

\subsection{Synthesis of Compounds}

(E)-3-[2,4-Bis(benzyloxy)phenyl] acrylic acid (2). To a solution of 2,4-bis(benzyloxy)benzaldehyde (1), $1.00 \mathrm{~g}$ (3.14 mmol, prepared from 2,4-dihydroxybenzaldehyde, $\mathrm{NaH}, \mathrm{BnBr}, \mathrm{DMF}(83 \%)$ ), and malonic acid $654 \mathrm{mg}(6.28 \mathrm{mmol})$ in pyridine $(5 \mathrm{~mL})$, piperidine $62 \mu \mathrm{L}(0.72 \mathrm{mmol})$ was added at $0{ }^{\circ} \mathrm{C}$. The mixture was stirred for $1 \mathrm{~h}$ at $80^{\circ} \mathrm{C}$ before the addition of water $(50 \mathrm{~mL})$ and conc. $\mathrm{HCl}(5 \mathrm{~mL})$ at $0^{\circ} \mathrm{C}$. The resulting suspension was filtered and rinsed with water $(10 \mathrm{~mL})$ to obtain crude 2 . The crude solid was dissolved in $1 \mathrm{M} \mathrm{NaOH} / \mathrm{MeOH}(2: 1,15 \mathrm{~mL})$, and neutralized by the slow addition of $1 \mathrm{M} \mathrm{HCl}(10 \mathrm{~mL})$, followed by filtration to afford purified 2 . 
General procedure for synthesis of 3-5. To a solution of aldehyde $1,500 \mathrm{mg}(1.57 \mathrm{mmol})$, and phosphonium salt (2.4 mmol, 2-carboxyethyltriphenylphosphine bromide $0.98 \mathrm{~g}$ for 3, 3-carboxypropyltriphenylphosphine bromide $1.01 \mathrm{~g}$ for 4, 4-carboxybutyltriphenylphosphine bromide $1.04 \mathrm{~g}$ for 5) in dry THF (4.7 $\mathrm{mL}) 0.58 \mathrm{~g}$ $\mathrm{t}$-BuOK was slowly added $(5.2 \mathrm{mmol})$ at $0{ }^{\circ} \mathrm{C}$ under argon. After being stirred for $2 \mathrm{~h}$ at room temperature, the reaction mixture was quenched with sat. $\mathrm{NH}_{4} \mathrm{Cl}$ aq. $(30 \mathrm{~mL})$. The resulting solution was extracted with ethyl acetate $(60 \mathrm{~mL})$ and the extract was washed with brine and dried over $\mathrm{MgSO}_{4}$. After filtration, the filtrate was concentrated in vacuo and the residue was purified by silica gel column chromatography (hexane/ethyl acetate $=90 / 10$ to $60 / 40$ ) to obtain 3-5.

General procedure for synthesis of E-C2,3,4,5. To a solution of 2-5 in ethanol ( $2 \mathrm{~mL})$, conc. $\mathrm{H}_{2} \mathrm{SO}_{4}$ $(10 \mu \mathrm{L})$ was added at room temperature. After being stirred at $80^{\circ} \mathrm{C}$ for $3 \mathrm{~h}$, the reaction mixture was diluted with water $(10 \mathrm{~mL})$ at room temperature. The resulting solution was extracted with hexane/ethyl acetate $(1: 1,10 \mathrm{~mL})$ and the extract was washed with saturated $\mathrm{NaHCO}_{3}$ aq. and brine successively and dried over $\mathrm{MgSO}_{4}$. After filtration, the filtrate was concentrated in vacuo and the residue was purified by silica gel column chromatography (hexane/ethyl acetate or dichloromethane/methanol) to obtain the corresponding ester.

To a solution of the above ester in methanol $(1 \mathrm{~mL})$ and ethyl acetate $(1 \mathrm{~mL}) 10 \mathrm{mg}$ palladium hydroxide $20 \%$ on carbon (wetted with ca. $50 \%$ water) was added under argon. After the vessel was purged with hydrogen, the reaction mixture was stirred under $1 \mathrm{~atm}$. of hydrogen at room temperature overnight. After the vessel was purged with argon, the reaction mixture was filtered to remove palladium hydroxide on carbon. The filtrate was concentrated in vacuo and the residue was purified by silica gel column chromatography (hexane/ethyl acetate or dichloromethane/methanol) to obtain E-C2,3,4,5.
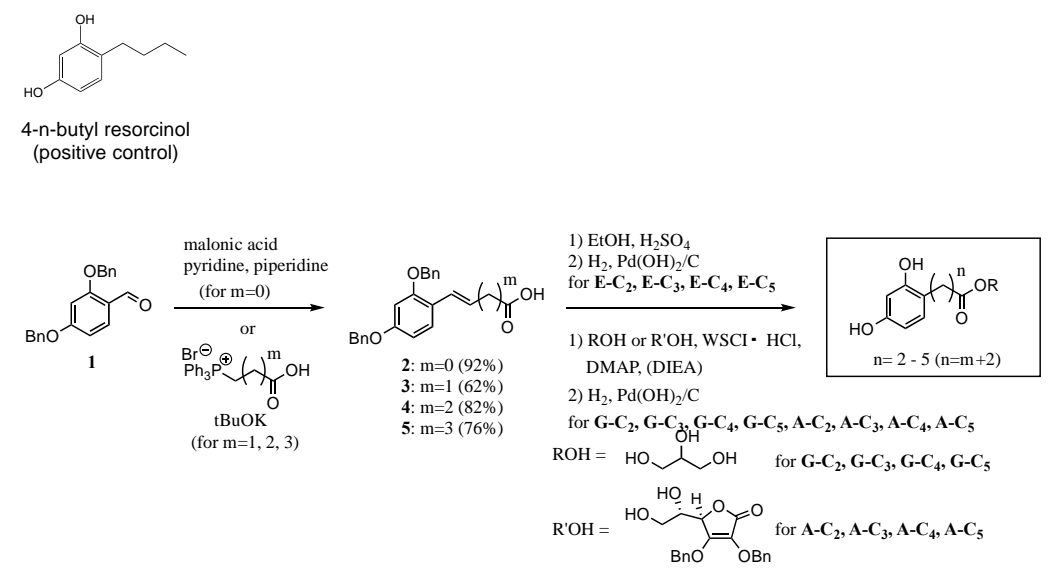

E- $\mathrm{C}_{2}: \mathrm{n}=2, \mathrm{R}=\mathrm{Et}(58 \%)$

E-C $\mathrm{C}_{3}: \mathrm{n}=3, \mathrm{R}=\mathrm{Et}(64 \%)$

E-C $\mathrm{C}_{4}: \mathrm{n}=4, \mathrm{R}=\mathrm{Et}(62 \%)$

E-C 5 : $\mathrm{n}=5, \mathrm{R}=\mathrm{Et}(58 \%)$

$\mathrm{G}^{-\mathrm{C}_{2}: \mathrm{n}=2, \mathrm{R}=\text { glyceryl }(56 \%)}$

$\mathrm{G}_{-} \mathrm{C}_{4}: \mathrm{n}=4, \mathrm{R}=\mathrm{g}$ gyceryl $(36 \%)$ G-C. 5 : $n=5, R=$ glyceryl $(33 \%)$

A- $\mathrm{C}_{2}: \mathrm{n}=2, \mathrm{R}=\mathrm{L}-\mathrm{ascorb}-6-\mathrm{yl}(40 \%)$ A-C
A-C A-C 5 : $:=5$, R=L-ascorb-6-yl (42\%)
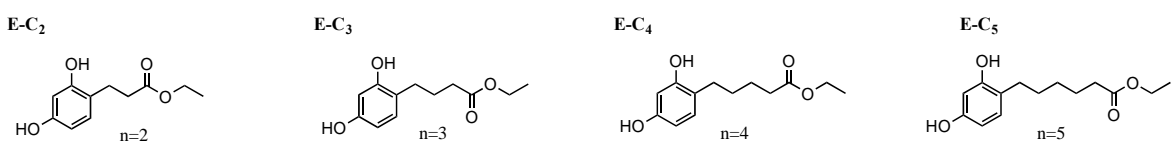

G-C 2<smiles>O=C(CCCc1ccc(O)cc1O)OCC(O)CO</smiles><smiles>O=C(CCCCc1ccc(O)cc1O)OCC(O)CO</smiles>

G-C 5<smiles>O=C(CCc1ccc(O)cc1O)OCC(O)CO</smiles>

A- $\mathrm{C}_{2}$

A- $\mathrm{C}_{3}$
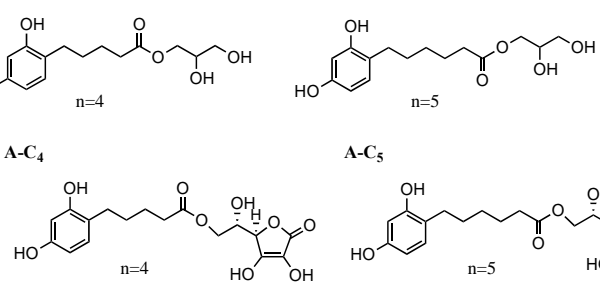

A- $\mathrm{C}_{5}$
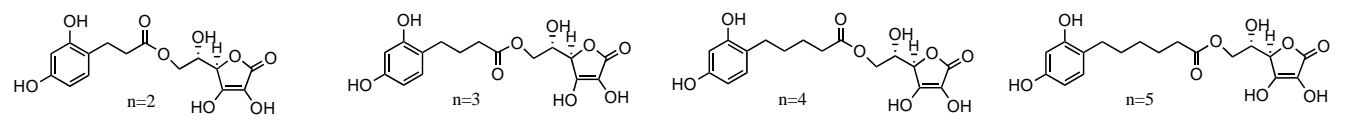

Figure 1. Synthetic pathway and structures of the resorcinol derivatives. 
Table 1. Sample name, molecular weight and cLogP of the resorcinol derivatives.

\begin{tabular}{|c|c|c|c|c|}
\hline Derivative & $\mathbf{R}$ & $\mathbf{N}_{-}^{*}$ & Molecular Weight & cLogP \\
\hline $\mathrm{A}-\mathrm{C}_{2}$ & \multirow{4}{*}{$\begin{array}{l}\text { L-Ascorb-6-yl } \\
\text { (group A) }\end{array}$} & 2 & 340 & -0.96 \\
\hline $\mathrm{A}-\mathrm{C}_{3}$ & & 3 & 354 & -0.58 \\
\hline $\mathrm{A}-\mathrm{C}_{4}$ & & 4 & 368 & -0.05 \\
\hline $\mathrm{A}-\mathrm{C}_{5}$ & & 5 & 382 & 0.48 \\
\hline $\mathrm{E}-\mathrm{C}_{2}$ & \multirow{4}{*}{$\begin{array}{c}\text { Ethyl } \\
\text { (group E) }\end{array}$} & 2 & 210 & 1.42 \\
\hline $\mathrm{E}-\mathrm{C}_{3}$ & & 3 & 224 & 0 \\
\hline E-C 4 & & 4 & 238 & 2.33 \\
\hline E-C ${ }_{5}$ & & 5 & 252 & 2.86 \\
\hline $\mathrm{G}-\mathrm{C}_{2}$ & \multirow{4}{*}{$\begin{array}{l}\text { Glyceryl } \\
\text { (group G) }\end{array}$} & 2 & 256 & -0.58 \\
\hline $\mathrm{G}-\mathrm{C}_{3}$ & & 3 & 270 & -0.21 \\
\hline $\mathrm{G}-\mathrm{C}_{4}$ & & 4 & 284 & 0.32 \\
\hline $\mathrm{G}-\mathrm{C}_{5}$ & & 5 & 298 & 0.85 \\
\hline
\end{tabular}

*The number of carbon atoms in the methylene chain $\left(-\left(\mathrm{CH}_{2}\right) \mathrm{n}-\right)$ between the benzene ring and the carbonyl group.

General procedure for synthesis of A-C2,3,4,5 and G-C2,3,4,5. To a solution of 2-5 in DMF ( $2 \mathrm{~mL} / \mathrm{mmol}) \mathrm{WSCI} \cdot \mathrm{HCl}$ (1.2 eq) and DMAP ( $0.1 \mathrm{eq})$ were added at room temperature. Furthermore, diisopropylethylamine (2.5 eq) was added for the synthesis of A-C2,3,4,5. After the mixture was stirred for $30 \mathrm{~min}$ at room temperature, 2,3-O-dibenzyl-L-ascorbic acid (prepared according to the literature of J. Mol. Struct., 687, 101 (2004); Org. Biomol. Chem., 3, 2450 (2005)) for A-C2,3,4,5 or glycerol for $\mathrm{G}-\mathrm{C} 2,3,4,5$ was added. The reaction mixture was stirred for $3 \mathrm{~h}$ at room temperature, followed by dilution with hexane/ethyl acetate $(1: 1,30 \mathrm{~mL})$. The resulting solution was washed with $1 \mathrm{M} \mathrm{HCl}$, saturated $\mathrm{NaHCO}_{3}$ aq., and brine successively and dried over $\mathrm{MgSO}_{4}$. After filtration, the filtrate was concentrated in vacuo, and the residue was purified by silica gel column chromatography (hexane/ethyl acetate or dichloromethane/methanol) to obtain the corresponding ester.

The above ester was hydrogenated according to the general procedure for the synthesis of E-C2,3,4,5 to afford A-C2,3,4,5 and G-C2,3,4,5.

\subsection{Cell Culture}

Murine B16 melanoma cells were purchased from the RIKEN Bio Resource Center Cell Materials Development Office (Tsukuba, Ibaraki, Japan). The cells were cultured in DMEM containing 10\% FBS at $37^{\circ} \mathrm{C}$ in a $5 \% \mathrm{CO}_{2}$ atmosphere.

\subsection{Measurement of Melanin Content}

Murine B16 melanoma cells were seeded in a 6-well plate at $0.3 \times 10^{5}$ cells/well and cultured for $24 \mathrm{~h}$. The medium was then replaced with fresh medium, supplemented with a final concentration of $0.1 \% \mathrm{DMSO}$, used as a control. Each resorcinol derivative was added to the medium to a final concentration of $10 \mu \mathrm{M} / 0.1 \%$ DMSO and incubated for $72 \mathrm{~h}$. A total of $100 \mu \mathrm{L}$ culture supernatant was transferred to a 96-well plate and the absorbance at $405 \mathrm{~nm}$ was measured with a microplate reader (SpectraMax M2e, Molecular Devices Co., Sunnyvale, CA, USA). The melanin content released in the medium was calculated from a melanin calibration curve. The cells were washed twice with PBS and detached with trypsin-EDTA. The cells were centrifuged at $50 \times \mathrm{g}$ for $10 \mathrm{~min}$ at room temperature (Himac CT6E, Hitachi Koki Co., Ltd., Tokyo, Japan). The supernatant was then removed, and the cell pellet was resuspended in medium. Living cells were stained with trypan blue using an aliquot of the suspension. The number of viable cells was then counted using a cell counter. The remaining suspension was centrifuged at $150 \times g$ for $10 \mathrm{~min}$ at room temperature. The supernatant was then 
removed and $1 \mathrm{~mL} 1 \mathrm{~N} \mathrm{NaOH}$ was added per $10^{6}$ cells. Next, cell membrane lysate was prepared by heating at $75^{\circ} \mathrm{C}$ for $90 \mathrm{~min}$. Then, centrifugation was performed at room temperature at $50 \times g$ for $10 \mathrm{~min}$, and $100 \mu \mathrm{L}$ of the supernatant was collected in a 96-well plate. The absorbance at $405 \mathrm{~nm}$ was measured with a microplate reader and the intracellular melanin amount was calculated from the melanin calibration curve. Finally, the total amount of melanin in the medium and cells was evaluated.

\subsection{Measurement of Cell-Free Tyrosinase Activity}

Each resorcinol derivative was adjusted to a final concentration of $1 \mu \mathrm{M} / 0.1 \%$ DMSO with 0.1 $\mathrm{M}$ phosphate buffer ( $\mathrm{pH}$ 6.8) to prepare the test solutions. A total of $50 \mu \mathrm{L}$ of each test solution and 100 units/mL mushroom-derived tyrosinase in $0.1 \mathrm{M}$ phosphate buffer $(\mathrm{pH}$ 6.8) were added into each well of a 96-well plate and preincubated at $37^{\circ} \mathrm{C}$ for $1 \mathrm{~min}$. Then, $50 \mu \mathrm{L} 2 \mathrm{mM} \mathrm{L-DOPA}$ in $0.1 \mathrm{M}$ phosphate buffer ( $\mathrm{pH}$ 6.8) was added and the absorbance at $475 \mathrm{~nm}$ was measured with a microplate reader at $37^{\circ} \mathrm{C}$ for $0-10 \mathrm{~min}$. Tyrosinase activity was calculated from the relative value obtained by adding $50 \mu \mathrm{L} \mathrm{0.1 \%} \mathrm{DMSO}$, prepared with $0.1 \mathrm{M}$ phosphate buffer ( $\mathrm{pH} 6.8$ ), as a control, and setting the control to $100 \%$ based on the following equation (Equation (1)):

$$
\text { Tyrosinase activity }(\% \text { of control })=\frac{\text { Abs of sample }_{10 \mathrm{~min}}-\text { Abs of sample }_{0 \mathrm{~min}}}{\text { Abs of control } 10 \mathrm{~min}-\text { Abs of control }_{0 \mathrm{~min}}} \times 100
$$

Equation (1). Formula to Calculate Tyrosinase Activity in a Cell-free System

\subsection{Statistical Analysis}

SAS software (SAS Institute Inc., NC, USA) was used for statistical analysis. Dunnett's test was used to identify significant differences.

\section{Results}

\subsection{Effect of Resorcinol Derivatives on Cell Viability}

The number of viable B16 melanoma cells following supplementation with $10 \mu \mathrm{M}$ 4-n-butylresorcinol and each of the resorcinol derivatives was determined. No significant changes in cell viability were seen with any of the sample additions, as shown in Figure 2a.

\subsection{Effect of Resorcinol Derivatives on Melanogenesis}

The melanin content in the B16 melanoma cells following supplementation with $10 \mu \mathrm{M} 4$-n-butylresorcinol and each of the resorcinol derivatives was determined. Although the effects varied, all of the resorcinol derivatives significantly decreased the melanin content, as shown in Figure $2 b$.

\subsection{Effect of Resorcinol Derivatives on Tyrosinase Activity}

The tyrosinase activity was measured following supplementation with $10 \mu \mathrm{M} 4$-n-butylresorcinol and each of the resorcinol derivatives. Although the effects varied, all of resorcinol derivatives significantly decreased the tyrosinase activity, as shown in Figure 2c.

\subsection{Structure-Activity Relationship of the Resorcinol Derivatives in Terms of their Tyrosinase Activity and Melanin Content}

A scatter diagram was prepared using the melanin content and cLogP values of the resorcinol derivatives. Total melanin content ( $y$-axis) was plotted against the cLogP value $(x$-axis) for each resorcinol derivative. There was a weak negative correlation between the total melanin content and an increase in the cLogP value $(r=-0.56)$, as shown in Figure 3a. Based on the scatter diagram constructed for the tyrosinase activity, the activity was reduced as the cLogP value increased when it was $<1$, and was enhanced as the cLogP value increased when it was $\geqq 1$, as shown in Figure $3 b$. 


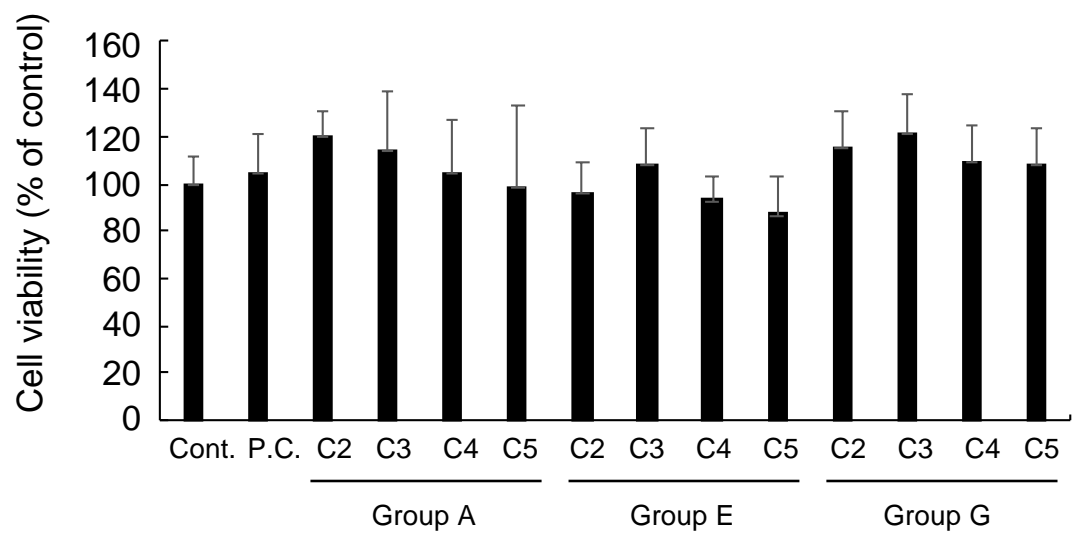

(a)

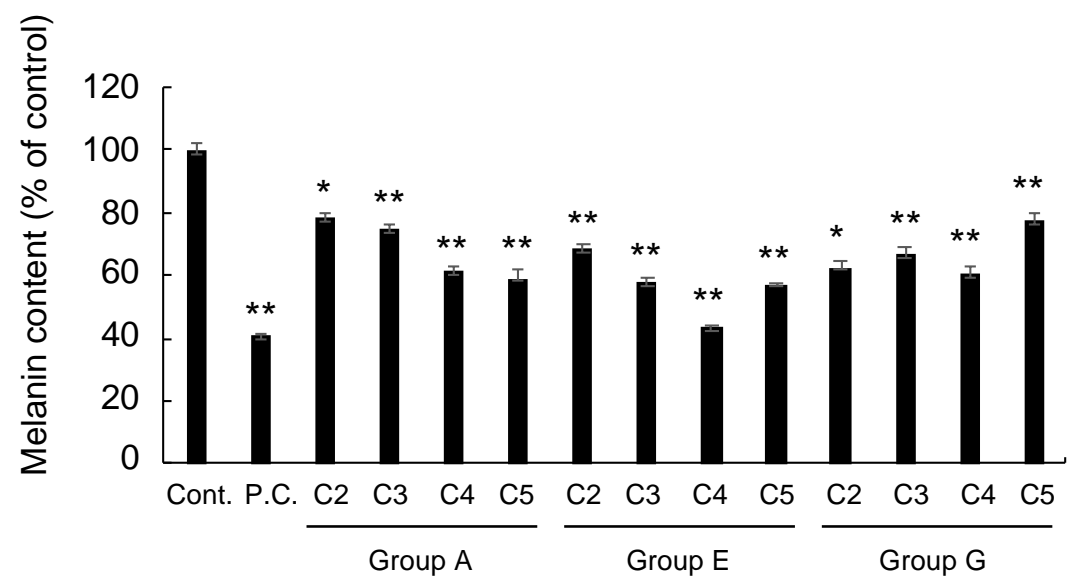

(b)

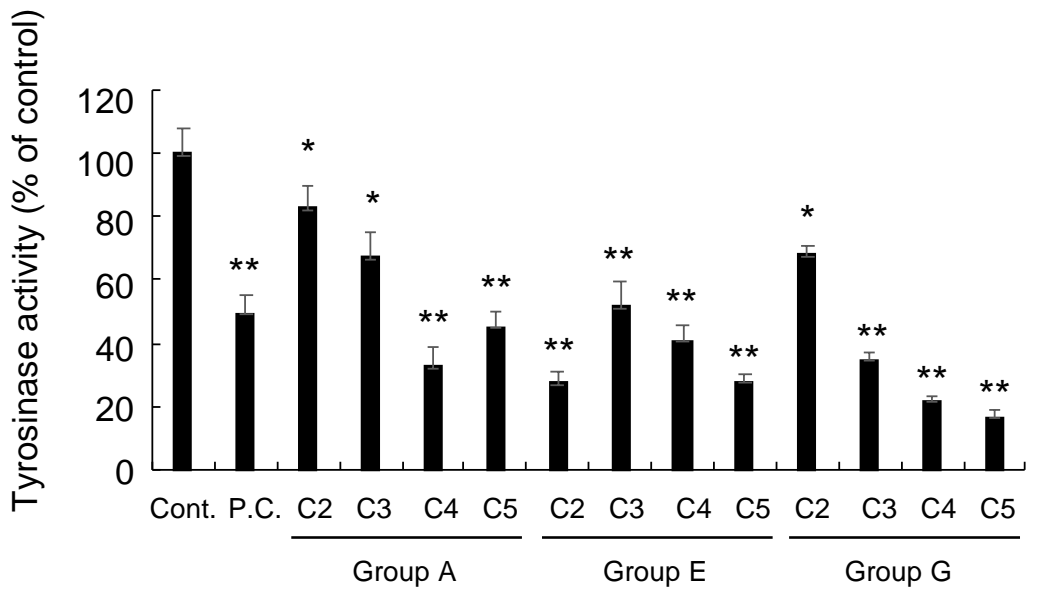

(c)

Figure 2. Effect of resorcinol derivatives on the cell viability of B16 melanoma cells (a), melanin content (b), tyrosinase activity (c). Data are the mean \pm S.D. of three experiments, ${ }^{*} p<0.05,{ }^{* *} p<0.01$ versus control (Dunnett's test). 


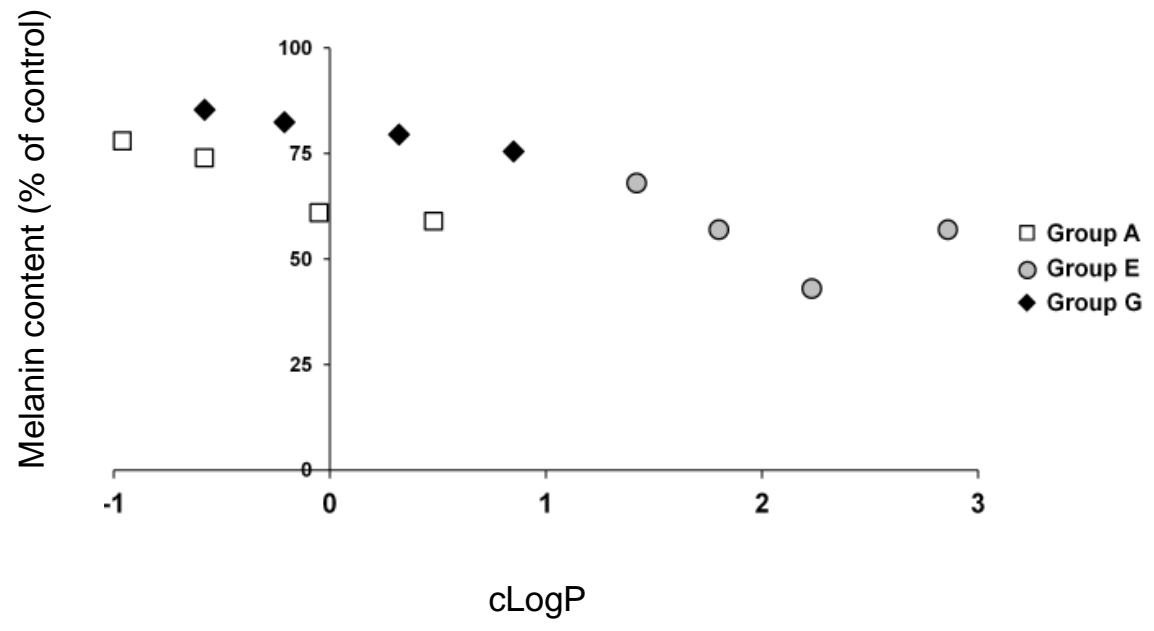

(a)

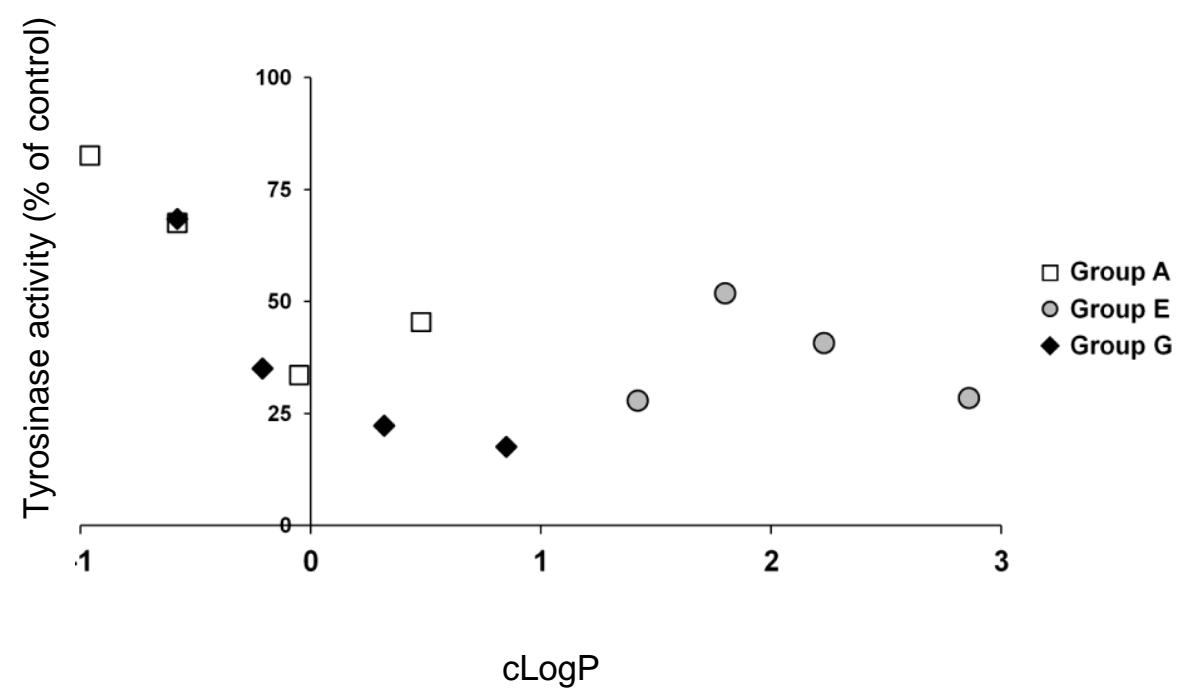

(b)

Figure 3. Correlation between cLogP versus melanin content and tyrosinase activity. Melanin content (a), tyrosinase activity (b).

\section{Discussion}

The present study aimed to evaluate the effects of synthesized resorcinol derivatives on cell viability and the amount of melanin produced in B16 melanoma cells. We also investigated the mechanism whereby melanin content is reduced using mushroom-derived tyrosinase.

This compound was designed based on the structure of 4-n-butylresorcinol. Without changing the active main component, resorcinol (1,3-hydroxybenzene), this formulation connects a carboxyl group to the alkyl chain of the rucinol. By incorporating resorcinol derivatives with various physical properties, the formulation aims to achieve a compound that is more effective and safer than 4-n-butylresorcinol. By lengthening the alkyl chain, lipid solubility is increased. The possibility of an effect arising from a change in the distance between the benzene ring and ester is also considered. Ethyl groups are fat soluble, glyceryl groups are neutral and water soluble, and ascorbyl groups are acidic and slightly more water soluble than glyceryl groups. In addition, ascorbyl groups are expected to provide synergistic effects. These ideas were used to design a compound with a high level of both safety and effectiveness. 
There are several studies that have evaluated the melanin production and tyrosinase inhibitory activity of resorcinol derivatives $[19,20]$, but there have been no reports discussing the relationship with $\log \mathrm{P}$ or cLogP.

The resorcinol derivatives ( $A-C_{2}$ to $A-C_{5}, E-C_{2}$ to $E-C_{5}$, and G- $C_{2}$ to $G-C_{5}$ ) did not significantly affect cell viability. The culture medium of the control group became black, owing to the release of melanin from the B16 melanoma cells. However, almost no color change was observed in the culture medium with added resorcinol derivatives. The absorbance of the culture medium was measured to quantitate the melanin content. The resorcinol derivatives significantly decreased the amount of melanin in the culture medium. The amount of melanin in the cells was significantly reduced when $\mathrm{A}-\mathrm{C}_{4}, \mathrm{~A}-\mathrm{C}_{5}, \mathrm{E}-\mathrm{C}_{3}, \mathrm{E}-\mathrm{C}_{4}, \mathrm{G}-\mathrm{C}_{2}$, and G-C $\mathrm{C}_{3}$ were added. A greater reduction in melanin content was obtained using the resorcinol derivatives described herein than in the positive control, 4-n-butylresorcinol.

To better understand the mechanism responsible for the reduction in melanin by treatment with the resorcinol derivatives, the effect on the tyrosinase activity, the rate-limiting enzyme of melanogenesis, was investigated using a cell-free system. The resorcinol derivatives significantly reduced the activity of the mushroom-derived tyrosinase. The compounds A- $\mathrm{C}_{4}, \mathrm{E}-\mathrm{C}_{2}, \mathrm{E}-\mathrm{C}_{4}, \mathrm{E}-\mathrm{C}_{5}, \mathrm{G}-\mathrm{C}_{3}, \mathrm{G}-\mathrm{C}_{4}$, and G-C reduced the tyrosinase activity more than the positive control. Similar to $4-n$-butylresorcinol, which is reported to exhibit potent tyrosinase inhibitory effects, $A-C_{3}$ to $A-C_{5}, E-C_{2}$ to $E-C_{5}$, and G-C $C_{2}$ to $\mathrm{G}-\mathrm{C}_{5}$ reduced the melanin amount without showing any cytotoxicity. These results suggest that the resorcinol derivatives may be useful for skin whitening.

Although A- $\mathrm{C}_{4}, \mathrm{E}-\mathrm{C}_{2}, \mathrm{E}-\mathrm{C}_{4}, \mathrm{E}-\mathrm{C}_{5}, \mathrm{G}-\mathrm{C}_{3}, \mathrm{G}-\mathrm{C}_{4}$, and G-C $\mathrm{C}_{5}$ showed potent tyrosinase inhibitory effects, these resorcinol derivatives did not affect the protein amount. This suggests that they directly inhibit tyrosinase activity to reduce the melanin content. As these resorcinol derivatives and the tyrosinase substrates, such as tyrosine and DOPA, have similar structures, the inhibition of tyrosinase by the resorcinol derivatives likely occurred in a competitive manner.

The relationship between the structure of each resorcinol derivative with the decreases in the melanin content and the tyrosinase inhibitory effects, was evaluated relative to their cLogP value. $\log \mathrm{P}$ is a numerical value that indicates the hydrophobicity of a compound. The partition coefficient $(\mathrm{P})$ is a value obtained by actually measuring the solubility ratio of a compound in water and in an organic solvent. Generally, the partition coefficient is expressed as $\mathrm{P}=$ (concentration in organic solvent phase)/(concentration in aqueous phase). The higher the value of $\mathrm{P}$, the lower the water solubility. In this manuscript, the values for $\operatorname{cLogP}$ were calculated to estimate the lipophilicity of the compounds. It is generally considered that the higher the lipophilicity, the better the ability of a compound to pass through the cell membrane and be taken up into cells. Scatter diagrams were constructed using total melanin content and $c \log P$ value, and tyrosinase activity and $\operatorname{cLogP}$ value. As the $c \log P$ value increased, the melanin content and tyrosinase activity reduced. In particular, at cLogP values $>1$, the tyrosinase activity was especially reduced. The cLogP value is related to the uptake of the resorcinol derivatives into the B16 melanoma cells and, hence, to the melanin content. By extension, the cLogP of the resorcinol derivative relates to the affinity between tyrosinase and the resorcinol derivatives.

Based on the results from the evaluation of melanin production, tyrosinase activity, and the cLogP value (an index for skin penetration), $\mathrm{E}-\mathrm{C}_{4}$ may serve as the most useful resorcinol derivative for skin whitening. However, as the present study was conducted at a cellular level, to enable the launch of $\mathrm{E}_{-} \mathrm{C}_{4}$ as a skin-whitening agent, it will be necessary to evaluate its efficacy and safety in humans. This should be performed after evaluating the effects of $\mathrm{E}-\mathrm{C}_{4}$ on melanin content by measuring its skin concentration in a three-dimensional cultured skin model and by evaluating its efficacy in a murine melanin model.

\section{Conclusions}

The resorcinol derivatives, $A-C_{3}$ to $A-C_{5}, E-C_{2}$ to $E-C_{5}$, and G-C $C_{2}$ to $G-C_{5}$, significantly reduced the melanin content produced in $\mathrm{B} 16$ melanoma cells compared with the control. Additionally, 
these resorcinol derivatives showed potent tyrosinase inhibitory effects and reduced melanin content at the low concentration of $10 \mu \mathrm{M}$. As these resorcinol derivatives exhibit less cytotoxicity than conventional whitening agents and, therefore, can be used at high concentrations, they are considered more useful as skin whitening agents.

Supplementary Materials: The following are available online at http://www.mdpi.com/2079-9284/7/3/55/s1. Supplementary Table S1 Synthesis of compounds.

Author Contributions: Conceptualization, Y.T. and I.H.; compounds synthesis, S.M. and I.H.; experiments with cells, T.H.; statistical analysis, Y.T. and T.H.; writing-original draft preparation, Y.T. and T.H.; writing-review and editing, Y.T. and I.H.; All authors have read and agreed to the published version of the manuscript.

Funding: This research received no external funding.

Acknowledgments: We thank Renee Mosi from Edanz Group (https://en-author-services.edanzgroup.com/) for editing a draft of this manuscript.

Conflicts of Interest: The authors declare no conflict of interest.

\section{References}

1. Ortonne, J.P. Normal and abnormal human skin color: From research to esthetics. Ann. Dermatol. Venereol. 2009, 136, S252-S256. [CrossRef]

2. Ortonne, J.P. Normal and abnormal skin color. Ann. Dermatol. Venereol. 2012, 139, S73-S77. [CrossRef]

3. Ortonne, J.P. La couleur de la peau normale ou anormaleNormal and abnormal skin color. Ann. Dermatol. Venereol. 2012, 139, S125-S129. [CrossRef]

4. Maddodi, N.; Jayanthy, A.; Setaluri, V. Shining light on skin pigmentation: The darker and the brighter side of effects of UV radiation. Photochem. Photobiol. 2012, 88, 1075-1082. [CrossRef] [PubMed]

5. Tsukamoto, K.; Jackson, I.J.; Urabe, K.; Montague, P.M.; Hearing, V.J. A second tyrosinase-related protein, TRP-2, is a melanogenic enzyme termed DOPAchrome tautomerase. The EMBO J. 1992, 11, 19-526. [CrossRef]

6. Yokoyama, K.; Suzuki, H.; Yasumoto, K.; Tomita, Y.; Shibahara, S. Molecular cloning and functional analysis of a cDNA coding for human DOPAchrome tautomerase/tyrosinase-related protein-2. Biochim. Biophys. Acta. 1994, 1217, 317-321. [CrossRef]

7. Kobayashi, T.; Urabe, K.; Winder, A.; Jiménez-Cervantes, C.; Imokawa, G.; Brewington, T.; Solano, F.; García-Borrón, J.C.; Hearing, V.J. Tyrosinase related protein 1 (TRP1) functions as a DHICA oxidase in melanin biosynthesis. The EMBO J. 1994, 13, 5818-5825. [CrossRef] [PubMed]

8. Jiménez, M.; Tsukamoto, K.; Hearing, V.J. Tyrosinases from two different loci are expressed by normal and by transformed melanocytes. J. Biol. Chem. 1991, 266, 1147-1156.

9. Tripathi, R.K.; Hearing, V.J.; Urabe, K.; Aroca, P.; Spritz, R.A. Mutational mapping of the catalytic activities of human tyrosinase. J. Biol. Chem. 1992, 267, 23707-23712. [PubMed]

10. Prota, G. Progress in the chemistry of melanins and related metabolites. Med. Res. Rev. 1988, 8, 525-556. [CrossRef] [PubMed]

11. Maeda, K.; Fukuda, M. Arbutin: Mechanism of its depigmenting action in human melanocyte culture. J. Pharmacol. Exp. Ther. 1996, 276, 765-769. [PubMed]

12. Kahn, V. Effect of kojic acid on the oxidation of DL-DOPA, norepinephrine, and dopamine by mushroom tyrosinase. Pigment Cell Res. 1995, 8, 234-240. [CrossRef] [PubMed]

13. Khatib, S.; Nerya, O.; Musa, R.; Tamir, S.; Peter, T.; Vaya, J. Enhanced substituted resorcinol hydrophobicity augments tyrosinase inhibition potency. J. Med. Chem. 2007, 50, 2676-2681. [CrossRef] [PubMed]

14. Ando, H.; Ryu, A.; Hashimoto, A.; Oka, M.; Ichihashi, M. Linoleic acid and alpha-linolenic acid lightens ultraviolet-induced hyperpigmentation of the skin. Arch. Dermatol. Res. 1998, 290, 375-381. [CrossRef] [PubMed]

15. Ando, H.; Funasaka, Y.; Oka, M.; Ohashi, A.; Furumura, M.; Matsunaga, J.; Matsunaga, M.; Hearing, V.J.; Ichihashi, M. Possible involvement of proteolytic degradation of tyrosinase in the regulatory effect of fatty acids on melanogenesis. J. Lipid. Res. 1999, 40, 1312-1316. [PubMed]

16. Imokawa, G.; Kobayashi, T.; Miyagishi, M.; Higashi, K.; Yada, Y. The role of endothelin-1 in epidermal hyperpigmentation and signaling mechanisms of mitogenesis and melanogenesis. Pigment Cell Res. 1997, 10, 218-228. [CrossRef] [PubMed] 
17. Kolbe, L.; Mann, T.; Gerwat, W.; Batzer, J.; Ahlheit, S.; Scherner, C.; Wenck, H.; Stäb, F. 4-n-butylresorcinol, a highly effective tyrosinase inhibitor for the topical treatment of hyperpigmentation. J. Eur. Acad. Dermatol. Venereol. 2013, 1, 19-23. [CrossRef] [PubMed]

18. Katagiri, T.; Okubo, T.; Oyobikawa, M.; Futaki, K.; Shaku, M.; Kawai, M. Novel melanogenic enzymes for controlling hyperpigmentation. In Proceedings of the 20th IFSCC International Congress, Cannes, France, 14-18 September 1998; Volume 39, pp. 1-11.

19. Tasaka, K.; Kamei, C.; Nakano, S.; Takeuchi, Y.; Yamato, M. Effects of Certain Resorcinol Derivatives on the Tyrosinase Activity and the Growth of Melanoma Cells. Methods Find Exp. Clin. Pharmacol. 1998, 20, 99-109. [CrossRef] [PubMed]

20. Shimizu, K.; Kondo, R.; Sakai, K.; Takeda, N.; Nagahata, T.; Oniki, T. Novel Vitamin E Derivative With 4-substituted Resorcinol Moiety Has Both Antioxidant and Tyrosinase Inhibitory Properties. Lipids 2001, 36, 1321-1326. [CrossRef] [PubMed]

(C) 2020 by the authors. Licensee MDPI, Basel, Switzerland. This article is an open access article distributed under the terms and conditions of the Creative Commons Attribution (CC BY) license (http://creativecommons.org/licenses/by/4.0/). 